\title{
A NOTÁVEL ABRANGÊNCIA DOS ESTUDOS LITERÁRIOS: UM PASSEIO PELO VOLUME 70 DA ELL
}

THE REMARKABLE SCOPE OF LITERARY STUDIES: A WALK THROUGH ISSUE 70 OF ELL

Lauro Iglesias Quadrado1 Juliana Ludwig Gayer² Felipe Flores Kupske ${ }^{3}$ Editores

Dividimos com nosso público leitor, com enorme satisfação, o novo número de Estudos Linguísticos e Literários, a ELL, revista dos Programas de Pósgraduação em Língua e Cultura e em Literatura e Cultura da Universidade Federal da Bahia (UFBA).

Antes de tudo, gostaríamos de agradecer a todos os autores pelo envio de suas submissões. Em nossa edição de n. 70, apresentamos o resultado de trinta e

\footnotetext{
Endereço eletrônico: lauroiq@gmail.com.

2 Endereço eletrônico: julianaludwig@yahoo.com.br.

3 Endereço eletrônico: kupske@gmail.com.
} 
duas pesquisas, um novo recorde de publicações em um mesmo volume da ELL. Disponibilizamos aqui, portanto, o fruto de intenso e avultado trabalho editorial de todas as partes envolvidas com a publicação do periódico: desde a avaliação até a edição final. Aproveitamos a oportunidade para deixar o nosso agradecimento também a todos os pareceristas e revisores que ajudaram na editoração deste número: somos dezenas de pessoas envolvidas que trabalham, em sua maioria absoluta, de maneira voluntária.

Ao analisarmos o material enviado para nós durante os meses de submissão podemos constatar, com o grande volume de contribuições (mais de 70 artigos foram enviados nesse período), que há enorme interesse pelos Estudos Literários e pelas possibilidades de discussão que eles propõem. Os textos que foram considerados para publicação na ELL encampam o tripé teoria/crítica/historiografia literária de maneira extremamente abrangente. Como editores, vemos na variada gama de contribuições compilada aqui uma contribuição importante para a expansão dos Estudos Literários como um campo do conhecimento que é, ao mesmo tempo em que consolidado academicamente, também palco de embates para deslegitimá-lo e reduzi-lo a segundo plano na arena pública.

O ato de leitura, individual ou coletivo, e o debate amplo e comunitário sobre obras de ficção proporcionam um alargamento da experiência social humana. É ao entrar em contato com outras narrativas, com as vivências e as expectativas de um Outro por vezes invisível, que o leitor desafia o seu próprio mundo e o retira de um lugar de risco: o de tornar o seu pensamento prisioneiro de seus próprios clichês pré-formatados.

Sendo assim, celebramos o acervo que passará a ser disponibilizado pela $E L L$, que conta com textos publicados que variam largamente entre si em temática e em corpus analisados. Ademais, também é motivo de satisfação para 
nós que contemos com produções de autorias diversas e oriundas de todas as cinco macrorregiões do Brasil.

Passemos então, finalmente, à apresentação dos artigos publicados neste volume tão especial.

Adriana Binati Martinez, em Memória(s) em La Distancia que nos Separa, apresenta uma leitura da construção da(s) memória(s) no romance La distancia que nos separa (2015), de Renato Cisneros, jornalista e autor peruano que alicerça a narrativa em liames tênues e porosos entre biografia, ficção e história abertos a múltiplos signos de compreensão. Nesta proposta analítica, a obra é lida como autoficção onde o narrador desenterra a figura paterna Luis Federico Cisneros Vizquerra - mais conhecido como El Gaucho Cisneros, general da División del Ejército Militar del Perú - para contestar a uma obsessão: a busca da identidade. Regressar ao passado apresenta-se como uma forma de ler o presente e a si próprio. A autora interpreta que o entendimento da memória é engendrada na ideia de uma construção permanente impugnando qualquer versão acabada dessas vivências, identidades e escrita narrada.

Thiago Andrade de Paula apresenta o texto O Discurso da Crítica: Genette, Leitor de Proust, que tem como objetivo realizar a leitura comparativa de dois textos decisivos de Genette sobre a obra maior de Marcel Proust, para se compreender a tensa relação que o romancista estabelece com o Realismo literário. $\mathrm{O}$ autor demonstra o ângulo do foco que é modificado entre o primeiro texto Proust Palimpsesto, em Figuras I (1972), no qual há uma tentativa de explicação da obra proustiana por meio de uma teoria da metáfora, e o segundo texto, O Discurso da Narrativa (1995), no qual há um tom bem mais sistemático fortemente influenciado pelo Estruturalismo, área do conhecimento muito familiar ao crítico francês. Ao se analisar e expor essa mudança fundamental dos 
frames em que são entendidos La Recherche, para o autor, percebe-se uma dificuldade para o Genette de palimpsesto de fazer jus à modernidade do texto em questão, enquanto que, para o Genette de O Discurso da Narrativa, a obra literária maior do escritor francês está intimamente ligada à arte moderna.

Raíssa Cardoso Amaral e Alfeu Sparemberger, em Considerações sobre a Memória Literária em Machado de Assis, Jorge Luis Borges e Alberto Mussa, amparados especialmente nas ideias de Tiphaine Samoyault (2008) acerca da intertextualidade, realizam uma leitura comparatista entre o capítulo VII, intitulado "O delírio", do romance Memórias póstumas de Brás Cubas ([1881] 2015), de Machado de Assis, o conto “O Aleph” ([1949] 2001), de Jorge Luis Borges, e o conto "A esfera fenícia", publicado na antologia Os contos completos (2016), de Alberto Mussa. A partir disso, buscam evidenciar a existência de uma memória literária que perpassa não apenas os textos literários, mas também os escritores que, no estudo, são considerados a mola propulsora dessa memória.

\section{Arlene Batista da Silva e Ana Carla Soares de Oliveira trazem Batucada no} Morro: A Presença da Roda de Samba no Conto Ana Davenga, da Autora Conceição Evaristo. $\mathrm{O}$ artigo tem como objetivo levantar discussões acerca da presença da roda de samba no conto Ana Davenga (1995), de Conceição Evaristo, a partir dos aspectos da tradição histórica. Inicialmente, reconhece-se a importância do samba como forma de divertimento para as comunidades afrobrasileiras, tendo em vista as influências culturais oriundas da África. Assim, busca-se apoio nos referenciais teóricos de Hermano Vianna na obra $O$ Mistério do Samba (1995), Feitiço Decente (2012) de Carlos Sandroni, O terreiro e a Cidade (2002) de Muniz Sodré, entre outros. No conto Ana Davenga, a roda de samba compõe o espaço da narrativa como o lugar de divertimento e alegria ao passo das batucadas. Ancorado em uma análise literária, o artigo reflete sobre as 
relações interartes - literatura e música -, com destaque para o legado deixado pelos povos em nossa tradição musical.

Sara Regina De Oliveira Lima e Maria Aline Porto Brito, em Miséria, Infância e Afrobrasilidade: Os Reflexos de uma Construção Nacional Assimétrica Retratados na Literatura de Conceição Evaristo, analisam as relações de miséria e infância nos contos "Zaíta esqueceu de guardar os brinquedos" e "Lumbiá" de Conceição Evaristo (2015), destacando as condições das crianças negras em situação de vulnerabilidade social a partir de uma literatura crítica, representativa e de resistência. Por ser uma pesquisa bibliográfica de caráter exploratório, baseia-se nos estudos empreendidos por Duarte (2010), Evaristo (2009), Engels (2010), Priore (2010), Santos (2017), dentre outros. As autoras observam que, ao ocupar, em grande parte, a margem da sociedade, crianças negras encontram-se cada vez mais distanciadas do suporte da família e do Estado, construindo suas vivências com base na violência, no trabalho infantil, bem como na negação dos seus direitos como mostra os contos analisados.

Mariane Rocha Silveira, Josiane Boff e Ivânia Campigotto Aquino apresentam o texto A Dualidade Cômica da Triste Figura: Um Estudo sobre a Carnavalização Barroca da Obra Don Quijote. Esse artigo tem como objetivos principais analisar a primeira parte da obra Don Quijote de La Mancha, de Miguel de Cervantes, El Ingenioso Hidalgo Don Quijote de La Mancha, à luz de Mikhail Bakhtin $(1981,2013)$ e apresentar algumas reflexões sobre as características do período em que foi escrita, o Barroco, com o apoio de López et al. (2004), Valentín (2010) e Villegas (2012). Para tanto, apresentam-se os principais pontos sobre a carnavalização e sua origem na Idade Média e as questões do riso e da dualidade de mundo, além do Barroco como importante período surgido de uma reação católica, que movimentou distintas instâncias, como a arte literária. Por meio da 
análise, mostram-se as dualidades como a loucura e razão, além da construção ficcional e a inspiração medieval.

Gabriela Fujimori da Silva apresenta o texto Os Silêncios de Kimiko em Sonhos Bloqueados, de Laura Hasegawa. Sonhos bloqueados, publicado no ano de 1991, é o primeiro romance de autoria de Laura Honda-Hasegawa. A personagemnarradora Kimiko é descendente de família japonesa e revela o imponente respeito à hierarquia familiar, atentando-se à tarefa de ser útil, cuidando dos familiares, especialmente sob as coordenadas da figura paterna. Diante desse contexto, o trabalho tem como objetivo analisar e compreender as formas de silêncio que marcam as vivências de sentimentos dúbios de Kimiko, que oscilam entre suas próprias vontades e a presença da cultura oriental que a impele às decisões paternas e aos ensinamentos familiares de obediência feminina. $\mathrm{O}$ trabalho tem como subsídio teórico os estudos de Eni Orlandi (1997), do historiador Oliveira Lima (1903) e de Inumaru (2019).

Ruan Nunes Silva, em Um Sentimento Tão Feio Quanto o Torpor, analisa de que formas o torpor, um afeto tradicionalmente lido como negativo, pode ser útil quando se interrogam as estruturas sociais heteronormativas. Para tanto, uma leitura do torpor na obra Chelsea Girls de Eileen Myles é realizada com o intuito de sublinhar as interpretações do estado de entorpecimento nas interações da protagonista da obra com o mundo ao seu redor. Considerando as contribuições de Muñoz (1999), Despentes (2016), Ahmed (2010) e outros, o autor conclui que o torpor é um afeto complexo que, em negociações que não estão isentas de sofrimento, revela inconsistências no cenário social político ao questionar o que se convencionou chamar de "sentimentos bons". Assim, o torpor se torna um “sentimento feio" com usos políticos possíveis. 
Paula Grinko Pezzini e Clarice Lottermann trazem o artigo O Gênero Policial na Narrativa Juvenil: Investigação de O Caso Dos Falcões-Peregrinos (2019), de Severino Rodrigues. A partir da narrativa O caso dos falcões-peregrinos (2019), do escritor pernambucano Severino Rodrigues, as autoras investigam os elementos clássicos, modernos e contemporâneos no que diz respeito ao gênero policial, bem como aspectos da literatura juvenil brasileira. A discussão parte de teóricos como Bordieu (1996) e Bakhtin (2006), em relação aos gêneros literários; Todorov (2006) e Fajardo (2018), no que concerne à ficção policial; e, para fundamentar a literatura juvenil, Lajolo e Zilberman (2007) e Luft (2010). As autoras constatam que a obra analisada justapõe aspectos do romance policial clássico e do moderno, transformando-se em uma narrativa de suspense contemporâneo.

Andressa Kelly Lima Moura, Maria Escolástica de Moura Santos e Carolina de Aquino Gomes apresentam o texto Literatura e Estética: Uma Análise Lukácsiana do Conto "O Verão Feliz Da Senhora Forbes", de Gabriel García Márquez. O trabalho parte da análise literária do conto O verão feliz da senhora Forbes, de Gabriel García Márquez, a partir da Estética de Georg Lukács. Essa narrativa aborda a rígida educação imposta por uma preceptora alemã a dois irmãos latino-americanos. A partir dela, é possível construir um estudo literário pertinente que, além de tratar de aspectos narrativos, propõe-se a trabalhar com a interdisciplinaridade reivindicada pela própria narrativa. Dessa forma, as autoras propõem um diálogo entre a literatura e a educação, de modo a elucidar os motivos da educação truculenta presente na obra e como a arte amplia e torna sensível este tema.

Meire Oliveira Silva apresenta o texto Meu Livro de Cordel Através de Tempos, Versos e Memórias: Resistências em Identidades. A obra de Cora Coralina ressoa na Literatura Brasileira como uma das mais genuínas vozes de mulheres 
a elevar a poesia popular e a cultura regional ao lugar de inquietações contemporâneas que atestam o caráter universal de suas produções. Mulher de educação tradicional e, talvez por esse motivo, desde cedo afastada das letras, conheceu o casamento, a rejeição familiar, o ofício de doceira e algum reconhecimento após o lançamento de seu primeiro livro apenas na maturidade, após os 70 anos de idade. No entanto, sua inclinação precoce à literatura junto a um olhar arguto para seu momento histórico a levou à realização de uma obra que transita por diversas temáticas, estilos e pautas entre tramas que aludem ao narrativo, ao lírico e ao memorialístico dos registros de lugares que reverberam como microcosmos de eventos históricos cujos ecos incidem sobre a contemporaneidade confirmando a atualidade de sua escrita. Assim, a análise de Meu livro de cordel (1976) alude a questões que dialogam (BAKHTIN, 1997) com os estudos de Literatura (CANDIDO, 2006), gênero (MACHADO, 2003) e memória (CANDAU, 2014).

Rafael Bonavina, com "Quára" do Jabuti: Reflexões sobre o Ciclo do Jabuti, levanta uma hipótese para explicar a supressão da tradução da palavra "quára" no conto VIII do ciclo do Jabuti encontrado em O Selvagem, de Couto Magalhães. O autor começa sua análise pelo gênero textual das narrativas, levando em conta diversas versões do ciclo do Jabuti. Em seguida, faz algumas considerações a respeito da caracterização do personagem em si mesmo. A partir dessas reflexões, o autor depreende que a supressão ocorreu por exigência do mercado editorial brasileiro do século XIX.

Júlia Nunes Azzi, com A Imensidão Dos Interiores: O Mergulho Introspectivo Nos Poemas De Marta Chaves, propõe um estudo sobre a poética de Marta Chaves, centrando-se no movimento de introspecção e reflexão que seus poemas apresentam e analisando-os como uma forma de procurar sentidos na 
interioridade do $e u$, em meio à solidão. O estudo concentra-se em três poemas do livro Varanda de inverno (2018): "Solar", "Banquete" e "Primeiro: continuar. Segundo: começar", objetivando compreender de que maneira é construída essa atmosfera íntima, através de uma análise das escolhas vocabulares e sonoras e das imagens criadas nos poemas, e, a partir disso, refletir sobre como essa introspecção carrega consigo a ideia de um descortinar do mundo, a partir da investigação do ser. Como aporte teórico, são utilizadas as ideias de teóricos como Gaston Bachelard (1978), Victor Chklovski (1971) e Iuri Tynianov (1975), dentre outros.

\section{Dauana Pinheiro Leal dos Santos apresenta Entre Desejos e Transgressões: A} Recepção da Obra Insubmissas Lágrimas De Mulheres na Plataforma Skoob. Nesse artigo, analisa-se o modo como os leitores, no contexto das mídias sociais, recepcionam a obra Insubmissas Lágrimas de Mulheres (2016), de Conceição Evaristo. Utiliza-se como método investigativo a análise de resenhas publicadas na plataforma Skoob. Busca-se averiguar os aspectos pelos quais o leitor é afetado pela escrevivência presente no livro. Constata-se que a identidade e a experiência do leitor moldam a forma de ler e avaliar a qualidade estética e literária da obra. Para a análise, foram selecionadas cinco resenhas enviadas pelos leitores da plataforma. Através desse exame, foi possível identificar uma substancial camada de leitores negros, a qual também abarca leitores que presenciaram ou compreendem as demandas de experiência das pessoas negras. O estudo se baseia nos pressupostos da Estética da Recepção, de Hans Robert Jauss (1979) e Jacques Rancière (2014).

Jéssica Maria Cruz Silva e Maria Suely de Oliveira Lopes, com Os Incêndios Criminosos sob o Olhar dos Esquecidos no Romance Palha de Arroz, de Fontes Ibiapina, analisam a obra Palha de Arroz, de Fontes Ibiapina (2004), tendo como 
foco a inter-relação entre ficção e história na construção de tal narrativa, que trata dos incêndios criminosos que aconteceram em bairros pobres de Teresina, capital do Piauí, durante a ditadura do Estado Novo. Escorado em autores como Costa Lima (1989), Pesavento (2006), Silva (2004), White (1994), que tratam da linha tênue entre literatura e história, bem como Lukács (2011) e Hutcheon (1991), no tocante às características do romance histórico, as autoras estabelecem uma reflexão crítica sobre o tema. Em linhas gerais, trata-se de um fato documentado, acrescido de outros recursos, próprios do novo romance histórico, como a ironia, a hipérbole, o grotesco, a reflexão em torno dos eventos narrados, construindose um texto em que história e literatura se relacionam.

\section{Michelle Márcia Cobra Torre, em História e Memória em O outono do} Patriarca de Gabriel García Márquez, discute as relações entre história e memória no romance O outono do patriarca, do escritor colombiano Gabriel García Márquez, publicado em 1975. A autora parte de uma discussão baseada em textos teóricos sobre memória e história, de pensadores como Paul Ricoeur, Michael Pollak, Hugo Achugar e Jacques Le Goff. O estudo enfoca como o patriarca, personagem do romance, forja uma memória oficial para o país que domina, e como, com a morte do ditador, outros relatos, que foram marginalizados e silenciados pela história oficial do governo, surgem na cena pública construindo outras histórias da pátria. Ressalte-se que o artigo aborda as relações da história com a literatura, no que se refere à ditadura e ao personagem patriarca do romance, bem como aborda as disputas pela memória e o desnudamento da narrativa histórica oficial, que justificava o poder absoluto do patriarca.

Leonardo Lopes Santos e Alexandra Santos Pinheiro apresentam o artigo Adão e Eva, de Tania Faillace, e a Revisão do Patriarcado. O trabalho busca explorar as relações do estabelecimento conceitual do patriarcado e as relações do 
feminismo e do feminino na obra da escritora Tania Jamardo Faillace, mais especificamente na novela Adão e Eva. No processo de análise, elencamos paralelos entre a tradição cultural e religiosa, seus contrastes e convergências com o texto faillaciano e a antropogonia judaico-cristã. $\mathrm{O}$ mote do trabalho é a amostragem dessas ideias abordadas pela autora em seu segundo livro, bem como propiciar uma abertura para a compreensão de conceitos comuns ao pensamento crítico do patriarcado, ainda oblíquo na sociedade contemporânea.

\section{Anderson Azevedo Ferigate e Teresinha V. Zimbrão Silva trazem Presença do} Hinduísmo na Poesia de Cecília Meireles Antes de Poemas Escritos na Índia. No contexto da literatura brasileira e fora dela, a obra poética da escritora Cecília Meireles (1901-1964) é bastante conhecida. No entanto, ainda há um aspecto dessa obra pouco estudado pela crítica literária, no que diz respeito ao diálogo ceciliano com as religiões, a saber, a intensa relação que a poeta estabeleceu com o Hinduísmo. O trabalho reflete sobre essa relação, analisando alguns poemas escritos antes de ela viajar para a Índia em 1953. As autoras apontam que estudar a presença do Hinduísmo nos poemas anteriores a essa viagem é, de fato, importante para compreender a obra da escritora como um todo.

Maria Clara Gonçalves e Raffaella Andréa Fernandez, em Carolina Maria de Jesus e o Teatro: Criações e Adaptações, apresentam e discutem a faceta dramatúrgica da escritora Carolina Maria de Jesus. Apesar de possuir uma obra literária que contempla diversos gêneros literários, alguns textos de Carolina permanecem desconhecidos do grande público, como é o caso do teatro. O trabalho busca sanar essa lacuna, apresentando e analisando duas peças inéditas de Carolina Maria de Jesus: A senhora perdeu o direito e Obrigado senhor vigário. 
Licilange Gomes Alves e Cid Ottoni Bylaardt, em Relações entre Linguagem e Morte em Lygia Fagundes Telles e Inês Pedrosa, propõem um diálogo entre as literaturas de Portugal e Brasil e usam como corpus As meninas (2009), de Lygia Fagundes Telles, e Fazes-me falta (2011), de Inês Pedrosa, com o objetivo de verificar como se dão as relações entre morte e linguagem nas obras. Para alcançar esse objetivo, são tomadas, especialmente, as considerações de Maurice Blanchot (1987; 1997) e Roland Barthes (2004; 1997); para apropriação de informações sobre as autoras, é usada a fortuna crítica de cada uma, como Sônia Régis (1998), Diana Navas e Telma Ventura (2017). Foram identificados pontos de encontro entre as escritoras, como a percepção de que as duas realizam um trabalho de esmerilhamento com a palavra literária, levantando reflexões em torno do próprio objeto laboral do escritor, a linguagem, e usam a temática fúnebre, também, para suscitar questões metalinguísticas.

Henrique Marques Samyn, em Anotações sobre o Neomedievalismo em Cantigas de Amares, de Leda Maria Martins, apresenta algumas considerações acerca de uma pesquisa em construção, cujo objeto central são composições poéticas presentes no livro Cantigas de amares, da escritora brasileira Leda Maria Martins. $\mathrm{O}$ artigo resgata as condições de emergência da investigação, no âmbito da trajetória acadêmica do pesquisador proponente; apresenta alguns apontamentos sobre o conceito de neomedievalismo na poesia brasileira, conforme proposto por Maria do Amparo Tavares Maleval; e expõe, em linhas gerais, a questão central da investigação proposta, ilustrando-a com alguns apontamentos iniciais sobre o poema intitulado "Cantiga 1".

Breno Fernandes, com Nação, Terreno do Duplo: A Função do Duplo na Mitologia do Estado Absolutista e do Estado-nação, faz uma leitura comparada entre a versão registrada por Plutarco do mito de Rômulo e Remo e a história das 
gêmeas Olanna e Kainene, personagens de Meio sol amarelo, romance da nigeriana Chimamanda Ngozi Adichie, que trata do surgimento e do esfacelamento de Biafra (atual Nigéria). O objetivo precípuo é sugerir que a figura do duplo, em ambas as narrativas, cumpre uma função mitológica comum relacionada à fundação tanto do Estado absolutista quanto do Estado-nação. A diferença que se observa tem a ver com o destino do duplo após o Estado ser fundado. No Estado absolutista, a presença do duplo humano torna-se empecilho, na medida em que o soberano passa a estabelecer uma relação de duplo com o próprio Estado, sendo necessário, portanto, o afastamento do duplo anterior, que por vezes se dá pela morte. Já no Estado-nação, que tem a fraternidade como um de seus pilares simbólicos, a presença do duplo é condição sine qua non não só para legitimar a fundação da nação, mas também para justificar sua continuidade.

\section{Weslei Chaleghi de Melo, Wilder Kleber Fernandes de Santana e Isabel} Cristina Cordeiro, com Nas Mãos do Artista, a Criação: A Literatura e o Cinema no Ensino do "Diferente", buscam focalizar as múltiplas formas de expressão artística que compenetram a linguagem, relacionando a literatura e o cinema. Para tanto, desenvolvem um diálogo que envolveu duas obras, uma literária (Elmer, o elefante xadrez) e outra cinematográfica (Dumbo). Os autores apresentam brevemente a função social da arte e como ela pode ser inserida dentro de diversas discussões em sala de aula com enfoque na diversidade, trabalhando com conceitos de arte e literatura na escola. Por meio da análise, foi possível constatar que ambas as obras apresentam temas pedagógicos e literariamente relevantes para a reflexão aqui proposta, ou seja, diversidade e educação por meio da literatura e do cinema se constituem como recursos valiosos e que despertam nos alunos e nos professores sentimentos de alteridade. 
Naiara Sales Araújo e Isadora Fernandes Figueiredo, em Literatura e Indústria Cultural: Um Estudo sobre Romance-Folhetim Como Cultura de Massa, refletem sobre a atuação da indústria cultural nas artes, primordialmente no romance-folhetim, por intermédio dos meios de comunicação. A partir dos estudos dos filósofos e sociólogos alemães Theodor Adorno (1903-1969) e Max Horkheimer (1895-1973), no que diz respeito a indústria cultural e cultura de massa, as autoras identificam como a literatura, mediante romances-folhetins, pôde tornar-se parte congruente da cultura de massa.

Valdinei José Arboleya apresenta Contemplando os Destroços do Futuro: A Memória Histórica Revestida de Ficção em $\mathrm{O}$ Conto $\mathrm{Da}$ Aia. Partindo das discussões sobre literatura, memória e história, o estudo objetiva analisar o romance distópico O conto da Aia ([1985] 2017), de Margareth Atwood, como um gênero literário capaz de retomar vestígios da memória. O autor sustenta a associação entre memória e distopia como algo que se fundamenta no argumento de que textos distópicos são formas de retomar a tradição, problematizando riscos sociais e políticos e ressignificando as questões decorrentes do campo da formação das identidades. Assim, o estudo propõe tecer algumas reflexões sobre os rastros do passado realocados sob a forma de ficção e ambientados em um futuro pós-apocalíptico no romance, mobilizando o conceito antropológico de valência diferencial dos sexos e o conceito de memória para estabelecer alguns caminhos comparativos entre as personagens deste romance e alguns arquétipos bíblicos.

Rafael Valles e Antônio Hohlfeldt, em O Eu em Perspectiva: Uma Análise sobre a Elaboração Metadiscursiva Em Los Diarios de Emilio Renzi (De Ricardo Piglia), analisam fragmentos dos três volumes de Los diarios de Emílio Renzi (PIGLIA, 2015-2017), procurando evidenciar uma intenção metadiscursiva que 
coloque em perspectiva a elaboração do eu. A partir de uma reflexão sobre por que e para quem o autor procura escrever um diário, sobre as implicações que isso gera na construção discursiva do eu e sobre a relação que essa escrita estabelece com o contexto sócio-histórico, os autores buscam entender de que forma Ricardo Piglia constrói a sua própria concepção de diário. $\mathrm{O}$ artigo tem como referências teóricas autores que analisam a questão do diário como forma (Simonet-Tenant, 2004; Blanchot, 2005; Lejeune, 2015; Giordano, 2017) e que analisam a obra do escritor argentino (Avelar, 2000; Orecchia Havas, 2019), entre outros.

\section{Jeniffer Geraldine Pinho Santos traz O Homo Sacer Contemporâneo e a} Necropolítica no Conto "Espiral" de Geovani Martins. A proposta desse artigo é, a partir do conto "Espiral", presente no livro O sol na cabeça (2018), do escritor brasileiro Geovani Martins, apresentar os conceitos: Homo Sacer, trabalhado pelo filósofo italiano Giorgio Agamben (2007), e Necropolítica, a política da morte, elaborado pelo filósofo camaronês Achille Mbembe (2018). As discussões levantadas a partir dos conceitos citados também são amparadas em Sueli Carneiro (2011) e Vladimir Safatle (2018). Com essa articulação, o texto interessa observar como a representação da desigualdade e da violência na literatura brasileira contemporânea contribui para debater questões sociais e políticas da contemporaneidade.

Gabrielle Forster apresenta Poetry Slam: Por uma Comunidade que Vem. Com sua performance corporal, seu ludismo e o desejo de partilha na esfera comum e cotidiana, o poetry slam se manifesta como expressão poética resistente tanto no âmbito dos temas quanto das formas, inovando os lugares de fala e os veículos de circulação do literário. Como acontecimento plural e democrático, fundado na experiência aberta do encontro e na tomada dos lugares de fala silenciados e marginalizados, os slams poéticos veiculam uma forma de comunidade 
diferenciada: inoperante, inconfessável e impossível, na linha das reflexões propostas por autores como Jean-Luc Nancy, Esposito, Blanchot e Agamben. Na desconstrução da acepção moderna de comunidade, tomada como núcleo atributivo e homogêneo, reside sua capacidade de resistência, enquanto renovadora de espaços, discursos e existências.

\section{Fabrizio Rusconi, com Giacomo Leopardi e Francesco De Sanctis sul Ruolo del} Vocabolario della Crusca alle Soglie del Risorgimento, aprofunda o pensamento de Giacomo Leopardi e Francesco de Sanctis, dois autores fundamentais do romantismo italiano. Ambos, no decorrer de sua atividade crítica e intelectual abordaram, em diferentes momentos, do ponto de vista histórico, a questão da língua italiana e da sua origem e formação, refletindo acerca da influência que o Vocabolario della Crusca e seus acadêmicos tiveram sobre a língua e sobre a literatura italiana. Leopardi dedica numerosos comentários do seu Zibaldone di pensieri (1817-1832) à questão da língua e ao Vocabolario della Crusca; De Sanctis, igualmente, considera a temática da Crusca e das suas políticas linguísticas na Storia della letteratura italiana (1870-71).

Margarete Maria Soares Bin, com \#Poemas na Rede, discute sobre o gênero poemas digitais que circulam na internet e pensa na formação do leitor jovem. Para tanto, a autora apresenta conceitos importantes como: conhecimentos em rede, poesia digital, hipertexto, multimodalidade, ciberespaço e o perfil do leitor da atualidade. Assim, várias leituras relacionadas ao tema são discutidas e o que se constata é que essa inovação tecnológica pode ser um meio para formar leitores do Ensino Médio, já que esses jovens fazem frequentemente uso dos meios eletrônicos e têm familiaridade com esses aparatos. 
Lucas Toledo de Andrade, em A Cidade Surreal na Poética Afro-brasileira Contemporânea: Um Olhar à Produção de Criolo, trata da produção do músico e compositor Criolo como parte da poética afro-brasileira contemporânea, a partir da leitura de algumas composições e dos recursos formais trazidos por elas. O foco desse trabalho está na percepção do modo como a cidade é representada nas letras e ritmos propostos pelo artista e da forma como essa representação possibilita uma percepção expandida da existência, permitindo a reflexão sobre o discurso historiográfico brasileiro e a condição do negro no país, o que se relaciona diretamente com o potencial crítico e revolucionário presente na imagem surrealista.

Irlomar Ferreira Martins e Marcos Frederico Krüger Aleixo, com Ruínas da Memória: As Metamorfoses de Manaus, em Dois Irmãos, de Milton Hatoum, analisam como questões sócio-históricas sobre o povo e a cidade de Manaus estão representadas na obra Dois Irmãos (2006), do escritor Milton Hatoum. Apoiada na memória, a ficção hatouniana revisita o passado de Manaus, suscitando a história de um povo que no decurso dos anos foi vítima das graves consequências do projeto de modernidade instaurado em solo manauara. Nael, o narradorpersonagem, trilha um percurso histórico e revela as metamorfoses pelas quais a sociedade e a capital amazonense passaram. Nesse processo, identificaram-se aspectos da crise da borracha que culminaram na criação da Cidade Flutuante, verificaram-se os impactos causados pelo projeto Zona Franca de Manaus, bem como os reflexos do militarismo na cidade por meio de personagens do romance. Com efeito, os ideais de progresso prestigiaram apenas a elite, enquanto a população tornou-se refém de inúmeros processos exploratórios.

Como podem ver, o cardápio está variadíssimo e há opções para todos os gostos. 
Que desfrutem de ótimas leituras!

Salvador, 10 dezembro de 2021

\section{Lauro Iglesias Quadrado \\ Juliana Ludwig Gayer}

Felipe Flores Kupske

Os editores do periódico Estudos Linguísticos e Literários 